\title{
Grouping theory of epidemiology
}

\section{— The Fifth Chapter of Theory about epidemiology}

\author{
Chaohui Zhang (Guangzhou, China) July 16,2021
}

Background (traditional theory) there are general and principle models and calculation formulas for epidemics, mainly the basic reproduction number $\mathrm{R}_{0}$ of a certain epidemic disease such as COVID-19, the newly confirmed number $\mathrm{C}_{\mathrm{n}}=\mathrm{R}_{\mathrm{n}-1} \mathrm{C}_{\mathrm{n}-1}$, The threshold of herd immunity is $\left(\mathrm{R}_{0}-1\right) / \mathrm{R}_{0}$.

Innovation theory Based on the fact that there are groups of different tends (that is, different $\mathrm{R}_{0}$ or $\mathrm{R}_{\mathrm{k}}$ ), a grouping model of epidemiology is proposed, and a complete and detailed calculation formula is given. The basic relationship is that the overall infection numbers of is equal to the sum of the infection number of groups, namely: $R_{t}=\sum\left(f_{k} R_{k}\right)$, where $\mathrm{f}_{\mathrm{k}}$ is the population proportion of each group, and $\mathrm{R}_{\mathrm{k}}$ is the basic reproduction number of each groups. Its important application is the grouping strategy in which prevention and control measures are inclined to high-risk groups. The basic relationship is that the basic reproduction number of each group is equal to the product of the control coefficient of its measures and the original basic reproduction number, namely: $R_{k}=\zeta_{k} R_{0 k}$. Compared with the traditional strategy of equal treatment, the grouping strategy has the characteristics of high efficiency, low consumption, and low threshold of herd immunity.

Keywords trend; grouping; differentiated treatment; influence value; contribution value; utility coefficient; control coefficient; vaccine; herd immunity

\section{About the author retired mechanical engineering teacher; Independent research, no tutors, no funds. Email: gzszcr16@gmail.com}

\section{Introduction}

Since the outbreak of the covid-19 epidemic for more than a year, apart from the success of vaccine research and development and the success of a few countries, the global response has been in chaos. The important reason lies in the backwardness of epidemic analysis and prevention and control measures and the lack of theory, which makes the response lack basis, there are serious differences and controversies. And even the so-called herd immunity strategy of natural infection can be popular and cause great harm. Therefore, filling the gaps and proposing effective theories is the top priority. This article discusses this. In the "Principle Model of Epidemic Infection Based on Differentiating R and Differential Treatment Strategies" in November 2020, I have proved that there are different trend groups in the population, and proposed a simple group analysis model and group prevention and control strategy . This article further demonstrates the principles, formulas and strategies of the model, which are referred to as grouping model and grouping strategy, collectively referred to as grouping theory. 


\section{Grouping models and formulas}

\section{Parameters and representations}

For simplicity, the basic reproduction number is represented by $\mathrm{R}$, the original basic reproduction number is $R_{0}$, and the basic reproduction number of the $\mathrm{k}$ group is $\mathrm{R}_{\mathrm{k}}$. The subscript of the symbol parameter can include the letter $k$ and the number $n . K$ represents the potential group, namely $k=a, b, c . .$. , where $k=t$ represents the whole, and $n$ represents the generation, such as $C_{a n} 、 C_{b(n-1)} 、 C_{t n} 、 A_{t n} 、 A_{t 15}$. When there is no need to distinguish between generations, subscripts do not use $n$, such as $R_{a} 、 R_{b} 、 R_{t}$, $f_{c} 、 f_{d} 、 r_{t} 、 r_{a}$. When there is no grouping, the subscript does not use $k$, such as $C_{n-1} 、 C_{0} 、 A_{n} 。 f_{k}$ represents the population proportion of the group, so $\mathrm{f}_{\mathrm{a}}+\mathrm{f}_{\mathrm{b}}+\mathrm{f}_{\mathrm{c}}+\cdots \cdots \cdot=\mathrm{f}_{\mathrm{t}}=1$.

There are many factors that affect the $\mathrm{R}$, mainly innate immunity, physical fitness and occupation (the degree of contact with the population, especially the infected carriers). The first two are closely related to age, and retirement is related to age. As a principle analysis, this article is divided into groups by age.

\section{The basic relationship of the principle model (without grouping)}

When without grouping, subscript $\mathrm{k}$ is no need, and its formula is the traditional principle formula:

The number of newly confirmed diagnoses: $\mathrm{C}_{\mathrm{n}}=\mathrm{R}^{\mathrm{n}}=\mathrm{RC}_{\mathrm{n}-1}$ and

the cumulative number of diagnoses: $A_{n}=\sum R^{n}$

$\because \sum \mathrm{R}^{\mathrm{n}}=\left(\mathrm{R}^{\mathrm{n}+1}-1\right) /(\mathrm{R}-1)$, when $\mathrm{R}^{\mathrm{n}+1}$ is large enough, $\sum \mathrm{R}^{\mathrm{n}} \approx \mathrm{R}^{\mathrm{n}+1} /(\mathrm{R}-1)$, and abbreviated as $\sum \mathrm{R}^{\mathrm{n}}$ $=\mathrm{R}^{\mathrm{n}+1} /(\mathrm{R}-1)$

$\therefore$ For covid-19 $R=3$, when $n \geqslant 5$, there is: $A_{n}=C_{n+1} /(R-1)=C_{n+1} / 2$

\section{Grouping principle model and formula}

Based on the existence of different $\mathrm{R}$, the grouping principle model introduces the basic reproduction number $\mathrm{R}_{\mathrm{k}}$ of each group. The following takes 3 groups $\mathrm{a}, \mathrm{b}$, and $\mathrm{c}$ as an example. The $\mathrm{R}$ of each group is $R_{a}, R_{b}, R_{c}$, and the basic reproduction numbers of the three groups are: the strong group $R_{a}$, the medium group $R_{b}$, the weak group $R_{c}$, and the whole is $R_{t}, C_{t n}$ is added as a whole. The principle is that when each group is not independent, the source of infection $\mathrm{C}_{\mathrm{k}(\mathrm{n}-1)}$ is allocated according to the population proportion $f_{k}$ of each group, that is: $C_{k(n-1)}=f_{k} C_{t(n-1)}$, and then each group infect according to its own $R$. Therefore, the formula and its derivation are:

$\mathrm{C}_{\mathrm{kn}}=\mathrm{R}_{\mathrm{k}}\left(\mathrm{f}_{\mathrm{k}} \mathrm{C}_{\mathrm{t}(\mathrm{n}-1)}\right)=\left(\mathrm{R}_{\mathrm{k}} \mathrm{f}_{\mathrm{k}}\right) \mathrm{C}_{\mathrm{t}(\mathrm{n}-1)}=\left(\mathrm{R}_{\mathrm{k}} \mathrm{f}_{\mathrm{k}} / \mathrm{R}_{\mathrm{t}}\right) \mathrm{C}_{\mathrm{tn}}$

Among them, $I_{k}=R_{k} f_{k}=R_{t} C_{k n} / C_{t n}$ is called the impact value of group $k$ on the epidemic, namely $R$.

Note: $\sum \mathrm{R}_{\mathrm{k}}=\mathrm{R}_{\mathrm{a}}+\mathrm{R}_{\mathrm{b}}+\mathrm{R}_{\mathrm{c}} \neq \mathrm{R}_{\mathrm{t}}=3$

From the formula (3), we can get: $R_{k}=\left(R_{t} / f_{k}\right)\left(C_{k n} / C_{t n}\right)$

Definition: $\mathrm{r}_{\mathrm{k}}=\mathrm{R}_{\mathrm{k}} \mathrm{f}_{\mathrm{k}} / \mathrm{R}_{\mathrm{t}}$ then $\mathrm{C}_{\mathrm{kn}}=\mathrm{r}_{\mathrm{k}} \mathrm{C}_{\mathrm{tn}}$,

$\mathrm{r}_{\mathrm{k}}=\mathrm{C}_{\mathrm{kn}} / \mathrm{C}_{\mathrm{tn}}$,

And: $C_{k n}=r_{k} C_{t n}, C_{t n}=C_{a n}+C_{b n}+C_{c n}=\left(r_{a}+r_{b}+r_{c}\right) C_{t n}$, 可得: $r_{t}=\sum r_{k}=r_{a}+r_{b}+r_{c}=1$

It can be seen that $r_{k}$ is the infection distribution coefficient of the group, and there are:

$\left(r_{a}+r_{b}+r_{c}\right)=\left(R_{a} f_{a} / R_{t}+R_{b} f_{b} / R_{t}+R_{c} f_{c} / R_{t}\right)=\sum\left(f_{k} R_{k}\right) / R_{t}=1$, 且 $I_{t}=f_{t} R_{t}=R_{t}$, so:

$\mathrm{R}_{\mathrm{t}}=\sum\left(\mathrm{f}_{\mathrm{k}} \mathrm{R}_{\mathrm{k}}\right)=\mathrm{I}_{\mathrm{t}}=\sum \mathrm{I}_{\mathrm{k}}$

\section{Practical calculation formula based on statistical data}

The above formula uses $C$ but not $A$, such as (4) formula $R_{k}=\left(R_{t} / f_{k}\right)\left(C_{k n} / C_{t n}\right)$, but the data of $C$ is very unstable in statistics, and the error is large, while A is relatively stable and the error is small, so when practical The formula for $\mathrm{A}$ is often used to replace the formula for $\mathrm{C}$. The specific derivation is as follows: 
$\because \mathrm{A}_{\mathrm{tn}}=\sum \mathrm{C}_{\mathrm{tn}}, \quad \therefore \mathrm{A}_{\mathrm{kn}}=\mathrm{C}_{\mathrm{kn}}=\sum\left(\mathrm{r}_{\mathrm{k}} \mathrm{C}_{\mathrm{tn}}\right)=\mathrm{r}_{\mathrm{k}} \sum \mathrm{C}_{\mathrm{tn}}=\mathrm{r}_{\mathrm{k}} \mathrm{A}_{\mathrm{tn}}$

$\therefore \mathrm{r}_{\mathrm{k}}=\mathrm{A}_{\mathrm{kn}} / \mathrm{A}_{\mathrm{tn}}$

Defined by $r_{k}$ and the above formula: $\quad R_{k}=r_{k} R_{t} / f_{k}=\left(R_{t} / f_{k}\right)\left(A_{k n} / A_{t n}\right)$

From the above, it can be obtained (subscript $\mathrm{n}$ omitted):

$$
\begin{gathered}
A_{k}=r_{k} A_{t}, C_{k}=r_{k} C_{t} 、 R_{k} f_{k}=r_{k} R_{t} \\
\sum A_{k}=A_{t} 、 \sum C_{k}=C_{t} 、 \sum\left(R_{k} f_{k}\right)=R_{t} \\
r_{x} / r_{y}=A_{x} / A_{y}=C_{x} / C_{y}=\left(R_{x} f_{x}\right) /\left(R_{y} f_{y}\right)
\end{gathered}
$$

Note that each group is not a closed body infected by independent sources of infection $\mathrm{C}_{\mathrm{k} 0}$ ( or $\left.\mathrm{C}_{\mathrm{k}(\mathrm{n}-1)}\right)$ and $R_{k}$. If it is regarded as a closed body, the principles, formulas, and results will be completely different. For example, the trend of each group will not be so different, otherwise the weak group with $\mathrm{R}=7$ will be all infected early, and the strong group with $\mathrm{R}$ less than 1 will not need to prevent and control because it will not be epidemic.

\section{Principles, formulas and analysis tables of grouping strategies}

\section{Control measures and their effects and parameters}

The assumptions and data in Table 1 and the following analysis are inaccurate, but because this article is the principle, trend and principle formula, especially basic, the main formula does not include specific data such as $C_{n} 、 C_{n-1} 、 A_{k} 、 A_{k n}$, etc., so Not affected by them. However, specific and accurate data, parameters and analysis are required in practical applications, such as $\mathrm{R}, \mathrm{A}, \mathrm{r}$, and $\zeta$. Therefore, the following tables and analyses use simplified data.

Generally, management and control measures are classified into different levels. Here, level 1 and level 2 are used to indicate gradual escalation of measures. The parameters changed after the measures are taken are still represented by the original names and symbols, while the parameters before the measures are called the original parameters and are indicated by subscript 0 . For example, the original basic reproduction number of the covid-19 is $\mathrm{R}_{0}=3$, and the basic infection after the measures The number is $\mathrm{R}_{\mathrm{t}}$. Define $\xi$ as the utility coefficient of the control measures, and the reduction of the basic reproduction number $\mathrm{R}$ is $\Delta \mathrm{R}$, then $\Delta \mathrm{R}=\xi \mathrm{R}, \Delta \mathrm{R}_{0}=\xi \mathrm{R}_{0}, \Delta \mathrm{R}_{\mathrm{k}}=\xi \mathrm{R}_{\mathrm{k}}$. Define $\zeta$ as the control coefficient, then $\mathrm{R}_{\mathrm{t}}=\zeta \mathrm{R}_{0}$, because $\mathrm{R}_{\mathrm{t}}=\mathrm{R}_{0}-\Delta \mathrm{R}_{0}=(1-\xi) \mathrm{R}_{0}=\zeta \mathrm{R}_{0}$, so $\zeta=(1-\xi)$, and the values of the two coefficients are both between 0 and 1. Accordingly, there are:

$$
\mathrm{R}_{\mathrm{k}}=\zeta_{\mathrm{k}} \mathrm{R}_{0 \mathrm{k}}, \quad \Delta \mathrm{R}_{0 \mathrm{k}}=\xi_{\mathrm{k}} \mathrm{R}_{0 \mathrm{k}}=\left(1-\zeta_{\mathrm{k}}\right) \mathrm{R}_{0 \mathrm{k}}
$$

The larger the $\xi$, the smaller the $\zeta$. For example, level 0 is uncontrolled natural infection, $\xi=0, \zeta=1$. level 1 is conventional prevention and control measures, such as wearing masks, washing hands frequently, etc., tracking and monitoring, isolation of carriers, $\xi=0.7, Z=0.35$. Level 1 - is Level 1 measures for poor execution. For example, it is only recommended, tracking and isolation are also poor, $\zeta=0.4 \sim 0.6$. Level 2 is Level 1 plus distance, $\zeta=0.3$. Level $2-, \zeta=0.35 \sim 0.45$. Level 3 is level 2 plus some special facility restrictions or even shut down, $\zeta=0.25$. Level 3-, $\zeta=0.3 \sim 0.4$. Level 3+ means home isolation, $\zeta=0.25 \sim 0.15$. Level 4 is level 3 plus general facilities such as schools, factories, shops, $\zeta=0.15$. level 4-, $\zeta=0.2 \sim 0.3$. level 5 is level 4 plus home isolation, severely restricted daily life, economic activities severe stagnation, $\zeta=0.1$. Level $5+$ means the area is blocked, $\zeta=0.05$. Let $\zeta_{\mathrm{k}}$ denote $\zeta$ of the k group. Customs blockade is an overall special measure. When $\xi=\left(\mathrm{R}_{0}-1\right) / \mathrm{R}_{0}, \mathrm{R}_{\mathrm{t}}=1$, and $\zeta=1 / \mathrm{R}_{0}$ at the same time, the curve of newly added diagnoses is flat. If the curve flattening is achieved by a sufficient proportion of the 
immunized population, it is called herd immunity.

\section{Production and analysis of management and control analysis table}

The original parameters $R_{0}$ and $f_{k}$ are calculated from the statistical data, and then $r_{k}=A_{k n} / A_{t n}$ is obtained from $A_{t n}$ and $A_{k n}$, and then $R_{k}=R_{t} r_{k} / f_{k}$, thus the original parameter table 1 is established. In addition, it is necessary to study statistics to obtain the control coefficient $\zeta$ of various control measures. They are the basis for the analysis, based on which the management and control analysis tables such as Tables 2, 3, 4, etc. can be established, and the herd immunity analysis table for vaccines can also be established

\section{Original data sheet}

Table 1 is based on the Italian epidemic data on March 11, 2020, but simplified it to four age groups, removes the death and $A_{k n}$ items, and increases the infection distribution coefficient of each group $r_{k}=A_{k n} / A_{t n}, R_{k}=R_{t} r_{k} / f_{k}$, and impact value $I_{k}=f_{k} R_{k}$. Although the data is not statistically complete and accurate, it has the significance of an example in principle. Therefore, the analysis and demonstration in principle can be carried out with this data.

Table 1. Covid-19 data sheet for four age groups

\begin{tabular}{|l|l|l|l|l|l|}
\hline $\mathrm{Gr}$ & Age & $\mathrm{f}_{\mathrm{k}}$ & $\mathrm{R}_{\mathrm{k}}=\mathrm{R}_{\mathrm{t}} \mathrm{r}_{\mathrm{k}} / \mathrm{f}_{\mathrm{k}}$ & $\mathrm{I}_{\mathrm{k}}=\mathrm{f}_{\mathrm{k}} \mathrm{R}_{\mathrm{k}}$ & $\mathrm{r}_{\mathrm{k}}=\mathrm{f}_{\mathrm{k}} \mathrm{R}_{\mathrm{k}} / \mathrm{R}_{\mathrm{t}}$ \\
\hline $\mathrm{a}$ & $0 \sim 29$ & 0.28 & 0.6 & 0.17 & 0.06 \\
\hline $\mathrm{b}$ & $30 \sim 49$ & 0.27 & 2 & 0.54 & 0.18 \\
\hline $\mathrm{c}$ & $50 \sim 69$ & 0.28 & 4 & 1.1 & 0.37 \\
\hline $\mathrm{d}$ & $\geq 70$ & 0.17 & 7 & 1.2 & 0.39 \\
\hline $\mathrm{t}$ & Whole & $\mathrm{f}_{\mathrm{t}}=\sum \mathrm{f}_{\mathrm{k}}=1$ & $\mathrm{R}_{\mathrm{t}}=\mathrm{R}_{0}=3$ & $\mathrm{f}_{\mathrm{t}} \mathrm{R}_{\mathrm{t}}=\mathrm{R}_{\mathrm{t}}=\sum\left(\mathrm{f}_{\mathrm{k}} \mathrm{R}_{\mathrm{k}}\right)$ & $\mathrm{r}_{\mathrm{t}}=\sum \mathrm{r}_{\mathrm{k}}=1$ \\
\hline
\end{tabular}

Wherein: Gr: Group; $\mathrm{f}_{\mathrm{k}}$ : Proportion of population Overall; $\mathrm{I}_{\mathrm{k}}$ : Impact value; $\mathrm{r}_{\mathrm{k}}$ : infection distribution coefficient .

\section{The impact value of the group on the epidemic and its key}

The number of newly confirmed diagnose $C_{k}=R_{k} f_{k} C_{t}$ in different groups is different, so the impact on the overall number of infections is different. Since $C_{t}$ is the same for each group, the impact can be described intuitively by the group's impact value $\mathrm{I}_{k}=\mathrm{f}_{\mathrm{k}} \mathrm{R}_{\mathrm{k}}$ or the proportional distribution coefficient $r_{k}=f_{k} R_{k} / R_{t}$. There are also related relations: $I_{t}=R_{t}=\sum I_{k}=\sum\left(f_{k} R_{k}\right), \sum r_{k}=r_{t}=1$ (Because the impact value $I_{k}$ varies with $R_{t}$, and the sum of $r_{k}$ is a constant 1 , sometimes $r_{k}$ is more convenient to compare the influence.). The influence assessment is mainly to compare $\mathrm{I}_{\mathrm{k}}$, but the key is $\mathrm{R}_{\mathrm{k}}$. For example, in Table 1: the $f_{k}$ of group a and group $c$ are the same, but $R_{k}$ is very different, the ratio of the two $I_{k}$ is the ratio of $R_{k}$ : $R_{a} / R_{c}=0.17 / 1.1=0.6 / 4=0.15$; group a and group $d$ The population ratio is 1.6 , but the ratio of $R_{k}$ is 0.09 , so the ratio of $I_{k}$ is $0.28 * 0.6 /(0.17 * 7)=0.14$, and the influence is much smaller. The $f_{k}$ of the $c$ group is much larger than $d$ group, but the $\mathrm{R}_{\mathrm{k}}$ is much smaller, so the impact value is similar. To sum up, the influence on the epidemic mainly depends on $R_{k}$, followed by $f_{k}$. Since $f_{k}$ is fixed and $R_{k}$ changes with measures, control measures should be tilted towards groups with large $R_{k}$.

\section{Contribution value of the group to the measure}

The reduction of the overall basic reproduction number after taking measures is $\Delta R=R_{0}-R_{t}$. The contribution of each group to $\Delta \mathrm{R}$ is different. Define $\mathrm{Q}_{\mathrm{k}}$ as the contribution value of the group to $\Delta \mathrm{R}$. Its definition and relational expression are (Note: the proof and derivation are omitted here. Note: $R \neq \sum R_{k}$, $\left.\Delta \mathrm{R} \neq \sum \Delta \mathrm{R}_{\mathrm{k}}\right)$ :

$\mathrm{Q}_{\mathrm{k}}=\mathrm{f}_{\mathrm{k}} \xi_{\mathrm{k}} \mathrm{R}_{0 \mathrm{k}}=\xi_{\mathrm{k}} \mathrm{I}_{0 \mathrm{k}}, \quad \mathrm{Q}_{\mathrm{l}}=\Delta \mathrm{R}=\mathrm{R}_{0}-\mathrm{R}_{\mathrm{t}}=\sum \mathrm{Q}_{\mathrm{k}}=\sum \xi_{\mathrm{k}} \mathrm{I}_{0 \mathrm{k}}$

It can be seen that the contribution value of the measure is proportional to $\xi_{k}, I_{0 k}$ or $\xi_{k}, f_{k}, R_{0 k}$. Since $f_{k}$ 
is a constant, the key is $\xi_{\mathrm{k}}$ and $\mathrm{R}_{0 \mathrm{k}}$. Therefore, if you want the strategy to achieve greater benefits, you should take measures with greater $\xi_{\mathrm{k}}$ for groups with greater impact value $\mathrm{I}_{0 \mathrm{k}}$, especially greater $\mathrm{R}_{0 \mathrm{k}}$, at this time the measure will have a multiplied contribution value. For example, in Table 4, group d only accounts for $17 \%$ of the population, but its $\mathrm{R}_{0 \mathrm{k}}$ is as high as 7 , and the utility coefficient is 0.8 . So although its utility coefficient $\xi_{\mathrm{d}}$ is only $1 / 7$ higher than the 0.7 of other groups, its contribution value of 0.95 is $20 \%$ higher than the 0.78 of the $c$ group. $c$ group has a population of $1 / 3$ more than him, and $R_{0 k}$ is $U p$ to 4 . It is even 8 times higher than group a, whose population is $1 / 3$ larger than his.

\section{Grouping strategy based on grouping model}

Based on the fact that different groups have different trends, namely R, the prevention and control of the epidemic should adopt a differentiated grouping strategy. The following examples discuss its principles.

\section{non-differentiated control strategy and its analysis}

Still taking the situation of the outbreak in Italy at that time and $\mathrm{R}=3$ as an example, the top priority at this time is to control the spread and reduce $\mathrm{R}$ to less than 1 . Therefore, it is necessary to adopt level 3-, and add customs blockade measures. According to this measure, Table 2 is obtained, where $R_{0 k}$ is the original $R_{k}$ of Table 1 , and $R_{k}$ is the basic reproduction number under control. It has two more than Table 1: control measures and $\zeta_{\mathrm{k}}$. Because the measures are the same, the $\zeta_{\mathrm{k}}$ of each group is the same, and they are all equal to $\zeta_{t}$, so $r_{k}$ does not change, but $\zeta_{t}$ changes with $R_{k}$.

This is similar to a measure taken by most countries, especially Western countries, when the epidemic is severe. Although the control measures are quite stringent and the epidemic is controlled, people over 70 are still in a severe situation with a high infection rate $R_{k}=2.3$, and high mortality rate. And the $0-29$ yearold population with a low $\mathrm{R}_{\mathrm{k}}=0.6$ is suffered from inefficient strict control, and so is subject to unnecessary strong negative effects.

Table 2 Analysis table under the same control measures. Let $\mathrm{R}_{\mathrm{t}}=1$, then $\zeta_{\mathrm{t}}=0.33$. Since $\zeta_{\mathrm{k}}$ is the same,

$\zeta_{\mathrm{k}}=\zeta_{\mathrm{t}}=0.33$.
\begin{tabular}{|l|l|l|l|l|l|l|l|l|}
\hline $\mathrm{Gr}$ & Age & $\mathrm{f}_{\mathrm{k}}$ & $\mathrm{R}_{0 \mathrm{k}}$ & MNS & $\zeta_{\mathrm{k}}$ & $\mathrm{R}_{\mathrm{k}}$ & $\mathrm{I}_{\mathrm{k}}$ & $\mathrm{r}_{\mathrm{k}}$ \\
\hline $\mathrm{a}$ & $0 \sim 29$ & 0.28 & 0.6 & L3- & 0.33 & 0.19 & 0.06 & 0.06 \\
\hline $\mathrm{b}$ & $30 \sim 49$ & 0.27 & 2 & L3- & 0.33 & 0.66 & 0.18 & 0.18 \\
\hline $\mathrm{c}$ & $50 \sim 9$ & 0.28 & 4 & L3- & 0.33 & 1.3 & 0.37 & 0.37 \\
\hline $\mathrm{d}$ & $\geq 70$ & 0.17 & 7 & L3- & 0.33 & 2.3 & 0.39 & 0.39 \\
\hline $\mathrm{t}$ & Whole & $\mathrm{f}_{\mathrm{t}}=1$ & 3 & Closure & 0.33 & 1 & 1 & $\mathrm{r}_{\mathrm{t}}=1$ \\
\hline
\end{tabular}

Wherein: MNS: control measures; L3-:Level 3-; $\mathrm{R}_{\mathrm{k}}=\zeta_{\mathrm{k}} \mathrm{R}_{0 k} ; \mathrm{I}_{\mathrm{k}}=\mathrm{f}_{\mathrm{k}} \mathrm{R}_{\mathrm{k}} ; \mathrm{I}_{\mathrm{t}}=\mathrm{f}_{\mathrm{t}} \mathrm{R}_{\mathrm{t}}=\mathrm{R}_{\mathrm{t}}=\sum\left(\mathrm{f}_{\mathrm{k}} \mathrm{R}_{\mathrm{k}}\right) ; \mathrm{r}_{\mathrm{k}}=\mathrm{f}_{\mathrm{k}} \mathrm{R}_{\mathrm{k}} / \mathrm{R}_{\mathrm{t}} ; \mathrm{r}_{\mathrm{t}}=\sum \mathrm{r}_{\mathrm{k}}=1$

\section{Differential treatment strategy and its analysis}

If we treat them differently, and adopt incremental control measures for each group in the order of high and low trend, very good results will be achieved. At this time, the control measures can be set first, $R_{k}$ and $I_{k}$ can be introduced by $\zeta_{\mathrm{k}}$, and $\mathrm{r}_{\mathrm{k}}$ can be used as verification, and then the control measures can be adjusted to obtain the target $\mathrm{R}_{\mathrm{t}}$. The following table shows the analysis of the differential treatment control measures, that have the same effect as the non-differential treatment control measures table 2, namely $R_{t}=1$.

Specifically: the measures of strong groups $\mathrm{a}$ and $\mathrm{b}$ are level 1 and 2 . but due to the poor execution of masks and distancing, the control coefficient $\zeta$ is only 0.5 and 0.4. The weaker groups $\mathrm{c}$ and $\mathrm{d}$ adopt stricter 3-,plus home isolation, and their control coefficient $\zeta$ reaches 0.3 . So the result is $\mathrm{R}_{\mathrm{t}}=1$. Although the 
restrictions on groups $\mathrm{c}$ and $\mathrm{d}$ have been stricter, their protection has also been strengthened. At the same time, the restrictions on groups $a$ and $b$ are greatly reduced, so the overall impact on the economy and life is much smaller.

Table 3. Analysis table of $\mathrm{R}_{\mathrm{t}}=1$ under different control measures

\begin{tabular}{|l|l|l|l|l|l|l|l|l|}
\hline Gr & Age & $\mathrm{f}_{\mathrm{k}}$ & $\mathrm{R}_{0 \mathrm{k}}$ & $\mathrm{MNS}$ & $\zeta_{\mathrm{k}}$ & $\mathrm{R}_{\mathrm{k}}=\zeta_{\mathrm{k}} \mathrm{R}_{0 \mathrm{k}}$ & $\mathrm{I}_{\mathrm{k}}=\mathrm{f}_{\mathrm{k}} \mathrm{R}_{\mathrm{k}}$ & $\mathrm{r}_{\mathrm{k}}=\mathrm{f}_{\mathrm{k}} \mathrm{R}_{\mathrm{k}} / \mathrm{R}_{\mathrm{t}} \mathrm{r}_{\mathrm{k}}$ \\
\hline $\mathrm{a}$ & $0 \sim 29$ & 0.28 & 0.6 & L1- & 0.5 & 0.3 & 0.08 & 0.08 \\
\hline $\mathrm{b}$ & $30 \sim 49$ & 0.27 & 2 & L2- & 0.4 & 0.8 & 0.22 & 0.22 \\
\hline $\mathrm{c}$ & $50 \sim 9$ & 0.28 & 4 & L3- & 0.3 & 1.2 & 0.34 & 0.34 \\
\hline $\mathrm{d}$ & $\geq 70$ & 0.17 & 7 & L3- & 0.3 & 2.1 & 0.36 & 0.36 \\
\hline $\mathrm{t}$ & Whole & $\mathrm{f}_{\mathrm{t}}=1$ & 3 & Closure & $\zeta_{\mathrm{t}}=\mathrm{R}_{\mathrm{t}} / \mathrm{R}_{0 \mathrm{t}}=0.33$ & $\mathrm{R}_{\mathrm{t}}=1$ & $\mathrm{R}_{\mathrm{t}}=1$ & $\mathrm{r}_{\mathrm{t}}=\sum \mathrm{r}_{\mathrm{k}}=1$ \\
\hline
\end{tabular}

If the enforcement for measures are differently, the control coefficients are different. For example, if the measures to wear mask are implemented well, then $\zeta=0.4$, plus social distancing is maintained well, then $\zeta=0.3$. For level $3+$ (plus home isolation) with strong execution, $\zeta=0.2$. At this time, $R_{t}=0.8$, which is a very good downward curve. The analysis is shown in the following table. It adds several items such as contribution value. The last four items are used for the analysis of the principle, and may not be listed in practice.

Table 4. Analysis table under the Differential measures, $\mathrm{R}_{\mathrm{t}}=0.8$

\begin{tabular}{|l|l|l|l|l|l|l|l|l|l|l|l|}
\hline $\mathrm{Gr}$ & Age & $\mathrm{f}_{\mathrm{k}}$ & $\mathrm{R}_{0 \mathrm{k}}$ & $\mathrm{MNS}$ & $\zeta_{\mathrm{k}}$ & $\mathrm{R}_{\mathrm{k}}=\zeta_{\mathrm{k}} \mathrm{R}_{0 \mathrm{k}}$ & $\mathrm{I}_{\mathrm{k}}=\mathrm{f}_{\mathrm{k}} \mathrm{R}_{\mathrm{k}}$ & $\mathrm{r}_{\mathrm{k}}$ & $\xi_{\mathrm{k}}$ & $\mathrm{f}_{\mathrm{k}} \mathrm{R}_{0 \mathrm{k}}$ & $\mathrm{Q}_{\mathrm{k}}$ \\
\hline $\mathrm{a}$ & $0 \sim 29$ & 0.28 & 0.6 & $\mathrm{~L} 2$ & 0.3 & 0.2 & 0.06 & 0.08 & 0.7 & 0.17 & 0.12 \\
\hline $\mathrm{b}$ & $30 \sim 49$ & 0.27 & 2 & $\mathrm{~L} 2$ & 0.3 & 0.6 & 0.16 & 0.22 & 0.7 & 0.54 & 0.38 \\
\hline $\mathrm{c}$ & $50 \sim 9$ & 0.28 & 4 & $\mathrm{~L} 2$ & 0.3 & 1.2 & 0.34 & 0.43 & 0.7 & 1.12 & 0.78 \\
\hline $\mathrm{d}$ & $\geq 70$ & 0.17 & 7 & $\mathrm{~L} 3+$ & 0.2 & 1.4 & 0.24 & 0.30 & 0.8 & 1.19 & 0.95 \\
\hline $\mathrm{t}$ & Whole & $\mathrm{f}_{\mathrm{t}}=1$ & 3 & Closure & $\zeta_{\mathrm{t}}=0.27$ & $\mathrm{R}_{\mathrm{t}}=0.8$ & $\mathrm{R}_{\mathrm{t}}=0.8$ & $\mathrm{r}_{\mathrm{t}}=1$ & 0.73 & 3 & $\mathrm{Q}_{\mathrm{t}}=2.2$ \\
\hline
\end{tabular}

Among them: $\mathrm{I}_{0 \mathrm{k}}=\mathrm{f}_{\mathrm{k}} \mathrm{R}_{0 \mathrm{k}}, \mathrm{Q}_{\mathrm{k}}=\xi_{\mathrm{k}} \mathrm{I}_{0 \mathrm{k}}, \zeta_{\mathrm{t}}=\mathrm{R}_{\mathrm{t}} / \mathrm{R}_{0 \mathrm{t}}, \mathrm{Q}_{\mathrm{t}}=\sum \mathrm{Q}_{\mathrm{k}}=\mathrm{R}_{0}-\mathrm{R}_{\mathrm{t}}$

\section{Analysis of Grouping Theory Applied to Vaccination}

There is no doubt that the grouping theory can be applied to the herd immunity analysis and strategy of vaccination. Its basic principle is: the product of the inoculation rate $X_{k}$ and the effective rate is the utility coefficient of vaccine prevention and control measures. What is interesting is that, based on intuition, countries generally implement a differentiated vaccination strategy, so which can be analyzed using grouping theory. The following table is based on a typical age distribution and vaccination rate distribution of the aging population in the United States. it makes a simplification: offset the invalid part of vaccines with the immunity rate formed by infection, so forming a $100 \%$ vaccine effective rate and zero infection immunity rate Simplified model, among them, the vaccination rate is the utility coefficient of vaccination. this table shows that according to its $95 \%$ vaccine effective rate, as long as the overall vaccination rate reaches $36 \%$, herd immunity can be achieved. Considering simplification and other errors, it can be considered that if the vaccination has an overall coverage rate of $45 \%$, herd immunity can be achieved. However, the traditional theory of non-grouping, only when the vaccine effective rate is $100 \%$, and the vaccination rate reaches $67 \%$ the herd immunity can be achieved. If the effective rate is $90 \%$, the vaccination rate must be $72 \%$. 
Table 5. Herd immunity analysis of vaccination under the grouping strategy. Among them: $\zeta_{k}=1-\xi_{k}=1-X_{k}$

\begin{tabular}{|l|l|l|l|l|l|l|l|l|}
\hline $\mathrm{Gr}$ & Age & $\mathrm{f}_{\mathrm{k}}$ & $\mathrm{R}_{0 \mathrm{k}}$ & $\mathrm{f}_{\mathrm{k}} \mathrm{R}_{0 \mathrm{k}}$ & $\mathrm{X}_{\mathrm{k}}$ & $\zeta_{\mathrm{k}}=1-\mathrm{X}_{\mathrm{k}}$ & $\mathrm{R}_{\mathrm{k}}=\zeta_{\mathrm{k}} \mathrm{R}_{0 \mathrm{k}}$ & $\mathrm{I}_{\mathrm{k}}=\mathrm{f}_{\mathrm{k}} \mathrm{R}_{\mathrm{k}}$ \\
\hline $\mathrm{a}$ & $0-29$ & 0.40 & 0.6 & 0.24 & 0.1 & 0.9 & 0.54 & 0.22 \\
\hline $\mathrm{b}$ & $30-49$ & 0.28 & 2 & 0.56 & 0.3 & 0.7 & 1.4 & 0.39 \\
\hline $\mathrm{c}$ & $50-69$ & 0.21 & 4 & 0.84 & 0.7 & 0.3 & 1.2 & 0.25 \\
\hline $\mathrm{d}$ & $\geq 70$ & 0.11 & 7 & 0.77 & 0.8 & 0.2 & 1.4 & 0.15 \\
\hline $\mathrm{t}$ & Whole & 1.0 & $\mathrm{R}_{0 \mathrm{t}}=2.4$ & $\mathrm{R}_{0}=2.4$ & 0.36 & $\zeta_{\mathrm{t}}=0.42$ & $\mathrm{R}_{\mathrm{t}}=1$ & 1. \\
\hline
\end{tabular}

Among them: $\quad \mathrm{R}_{0}=\sum\left(\mathrm{f}_{\mathrm{k}} \mathrm{R}_{0 \mathrm{k}}\right)=2.4, \quad \mathrm{X}_{\mathrm{t}}=\sum \mathrm{f}_{\mathrm{k}} \mathrm{X}_{\mathrm{k}}=0.36, \quad \zeta_{\mathrm{t}}=\mathrm{R}_{\mathrm{t}} / \mathrm{R}_{0}=1 / 2.4=0.42 \quad\left(\xi_{\mathrm{t}}=1-\zeta_{\mathrm{t}}=0.58\right)$

From March to May in the United States, Texas and Florida, which "should" have soared due to the adoption of full liberalization measures, but had the same decline in the epidemic as California and New York, which adopted the lockdown strategy. This puzzled experts. . According to guruin.com data, their (adults?) vaccination rates on May 25 were: $43 \%$ in Texas, $48 \%$ in Florida, 55\% in California, and 54\% in New York. According to traditional theory, this is far from reaching the $67 \%$ herd immunity requirement, and it is impossible to completely open up without increasing but falling. However, it can be easily explained by the analysis of the grouping theory as shown in the above table: their vaccination rates have reached or close to $36 \%$, plus natural reserved epidemic prevention habits and measures, such as some people wear masks, customs sealing etc., so R is already less than 1. It is equivalent to achieving herd immunity.( Another important reason is that its relatively young and aging population structure makes its basic reproductive number $\mathrm{R} 0=2.4$ much smaller than 3 , and the traditional herd immunity threshold is not $67 \%$ but $58 \%$.)

\section{Concluding remarks}

For Covid-19, there are significant and distinguishable groups. This fact determines that when the epidemic is severe, a different prevention and control strategy must be adopted. This is an important principle for prevention and control of the epidemic. Based on the above analysis, it can be seen that the grouping strategy not only doubles the result with half the effort, but also reduces or even avoids blockades and ensures economic operation. The non-differential treatment strategy is not only half the effort, but also huge losses. This article provides basic principles, formulas and analysis tables. The analysis table is just a principle model based on statistics and general experience. It includes a large number of simplifications and approximations, which are equivalent to ideal models and smooth curves of formulas. Therefore specific analysis and application are required in application. In actual prevention and control, the groups can be divided into more detailed groups, and different groups and strategies can also be used. For example, front-line medical staff are both high-risk groups and cannot be isolated, and they need highintensity protection. 